\title{
Comparison of renal arterial resistive index in type 2 diabetic nephropathy stage 0-4
}

\author{
Sharareh Sanei Sistani (1), Ali Alidadi (2), Alireza Ansari Moghadam (3), Fatemeh \\ Mohamadnezhad (1), Bahareh Heshmat Ghahderijani (1) \\ (1) Department of Radiology, School of Medicine, Zahedan University of Medical Sciences, \\ Zahedan, Iran; (2)Department of Nephrology, Faculty of Medicine, Zahedan University of \\ Medical Sciences, Zahedan, Iran; (3) Health Promotion Research Center, Zahedan University \\ of Medical Sciences, Zahedan, Iran
}

This article is distributed under the terms of the Creative Commons Attribution Noncommercial License (CC BY-NC 4.0) which permits any noncommercial use, distribution, and reproduction in any medium, provided the original author(s) and source are credited.

\begin{abstract}
Chronic kidney disease (CKD) is one of world health problems and its prevalence and incidence is increasing. Chronic Kidney Failure involves a range of pathophysiologic processes that are associated with impaired renal function, leading to cardiovascular morbidity and mortality. Renal artery resistive index (RI) is indicator of atherosclerotic change in small vessels. The current study was aimed to assess RI in diabetic nephropathy patients at stage 0-4 and to compare RRI with HbA1c, systolic blood pressure, diastolic blood pressure, albuminuria and glomerular filtration rate (GFR). In this cross sectional study,100 diabetic nephropathy patients who attend to nephrology clinic of Ali-ibn Abi Talib Hospital were entered to the study. Ultrasound Doppler renal resistive index was measured and other information was recorded from their last lab data that was recorded in their medical records. Variable included: systolic blood pressure, diastolic blood pressure, albuminuria, GFR, HbA1c. All data was analyzed by Pearson's Correlation Coefficient. The findings indicated a significant correlation of RI with systolic BP ( $\mathrm{p}=0.04$ $\mathrm{R}=0.75)$, microalbuminuria $(\mathrm{P}=0.001 \mathrm{R}=0.67)$, and $\mathrm{GFR}(\mathrm{P}=0.001 \mathrm{R}=0.76)$, while diastolic $\mathrm{BP}$ $(\mathrm{P}=0 / 45 \mathrm{R}=0 / 32), \mathrm{HbA} 1 \mathrm{c}(\mathrm{P}=0 / 56 \mathrm{R}=0 / 43)$ were not found to be associated with $\mathrm{RI}$. The findings indicated that increased systolic blood pressure, albumin excretion (microalbuminuria) and severity of disease were capable of increasing RI values in diabetic nephropathy patients. In addition, decreased GFR.
\end{abstract}

Key Words: Chronic kidney disease, Ultrasound Doppler renal resistive index, Renal arterial resistive index, Diabetic nephropathy.

Eur J Transl Myol 29 (4): 307-312, 2019

Chronic Kidney Failure (CKD) involves a range of pathophysiologic processes that are associated with impaired renal function. CKD is considered to be associated with cardiovascular morbidity and mortality. Relevant risk factors for CKD include hypertension, type 2 diabetes (T2DM), autoimmune diseases, high age, race, family history of kidney disease, history of acute renal failure and abnormal kidney structure and urinary tract. ${ }^{1,2}$ CKD was reported to be 27 th causes of total number of mortality worldwide in 1990 , while rose to 18th in 2010 with an annual death rate of 16.3 per 100 000 individuals. $^{3}$ The incidence of end-stage kidney disease varies from country to country, depending on regions, when $80 \%$ of individuals receiving therapeutic interventions for end-stage kidney disease are in rich countries with an elderly population. While fewer patients receive treatment in poorer countries, mainly due to the lack of acceptance of patients for renal replacement programs (RRTs), although they are rising dramatically. ${ }^{4}$ The prevalence of T2DM has been indicated to be increased all over the world, leading to enhanced burden of disease on both patients and health care systems. ${ }^{5}$ Diabetic nephropathy (DN) as a common complication of diabetes is initially linked to a slight increase in urinary albumin excretion microalbuminuria, and reduction in glomerular filtration rate (GFR), leading to all-cause and cardiovascular mortality in the T2DM patients and in the general population. ${ }^{6-8}$ Detection and staging of chronic kidney disease is depended on glomerular filtration rate and albuminuria level measurements. ${ }^{1}$ For renal function, there is not complete consensus about relationship of arterial stiffness with decline. In addition, currents 
evidence suggests that carotid-femoral aortic pulse wave velocity (PWV) gold standard is able to predict MA onset and is inked to annual change in eGFR, and decreased renal function in CKD subjects, but not general population. $^{9,10}$ Recent investigations revealed that therapeutic intervention at a very early stage, before proteinuria, is capable of preventing the onset of nephropathy. ${ }^{11}$ Early vascular pathological changes have been defined to lead to end-organ dysfunction, which are explained to be capable of predicting cardiovascular changes in high-risk individuals such as diabetic patients. $^{12,13}$ Renal resistive index (RI) has been described as a duplex ultrasound-derived parameter for exhibiting the arterial waveform, where RI is capable of demonstrating dynamic or structural changes of intrarenal vessels and renal dysfunction, ${ }^{14-16}$ and is markedly associated with renal arteriolosclerosis, and adverse cardiovascular events. Normal RI in adults is ranged from 0.47 to 0.70 , showing a difference between 5 to $8 \%$ for two kidneys. ${ }^{17-23} \mathrm{RI}$ is currently applied as a valuable marker for renal vascular and interstitial damage, ${ }^{24,25}$ where increased value of RI has shown negative progression of renal disease in T2DM patients, ${ }^{26}$ however, its clinical importance has been discussed. ${ }^{27,28}$ Current study was aimed to evaluated renal arterial resistive index in diabetic nephropathy (stage 0-4) among patients with type 2 diabetes.

\section{Materials and Methods}

All T2DM patients with the 0-IV stages (100 patients) referred to the Ali-ibn Abi Talib Hospital were enrolled in the study during 2015-2016. Patients who had kidney failure for any reason other than diabetes were not included. In addition, patients with diabetic nephropathy that were under hemodialysis or peritoneal dialysis were not included in the study. Additionally, smoker individuals with diabetic nephropathy were excluded as a risk factor for vascular disease. Informed consent was obtained from patients based on the approval of the Ministry of Health and Medical Education, Iran. In this study, sampling was done by census method and the whole medical records of patients were considered. The blood pressure (systolic and diastolic), glycosylated hemoglobin, serum creatinine, albuminuria, and 24-hour urine were extracted from the patient's medical records and recorded in a special form. Each patient was referred to an ultrasound unit and the Value of Intrarenal Resistive Index was measured in 3 poles (upper-middle-lower). The average rate in the 3 poles was recorded.

\section{Data analysis}

To describe the data, central indicators and dispersion (mean and standard deviation) were used and Pearson. Statistical significance was considered as $\mathrm{p}<0.05$.

\section{Results}

In the study, 100 patients with diabetic nephropathy were evaluated in a one-year period. Among 100 patients, 61
(61\%) were female and $39(39 \%)$ were male. The patients' age ranged from 27 to 71 years and mean age was $51 \pm 3$. All patients were sent to the ultrasound unit of Ali-ibn Abi Talib Hospital in Zahedan, Iran after recording the demographic data and the results of tests such as urinary albumin excretion and GFR calculation. Doppler ultrasonography was performed to determine the RI. Of these patients, the lowest nomber was in stage one (16 subjects), the highest number was in the third stage with 37 subjects (Table 1). In the current study, the standard of hypertension was considered to be greater than $130 \mathrm{~mm} \mathrm{Hg}$ for systolic pressure and greater than 80 $\mathrm{mmHg}$ for diastolic pressure (Table 2). Our results showed that about $57 \%$ of patients experienced systolic blood pressure higher than normal, while this was $34 \%$ for diastolic pressure. Meanwhile, the highest systolic and diastolic blood pressure was observed in Stage 4 and the lowest in Stage 2. In our study population, the overall RI index was $0.76 \pm 0.09$, which showed the highest level in stage 4 with a mean of $0.83 \pm 0.09$ and the lowest was seen in stage 1 with a mean of $0.63 \pm 0.03$. More data is given in Table 3. The One-Way ANOVA test showed that the mean RI in stage 4 was significantly more than stage 1,2 and $3(P=0.001)$, but the mean RI between stages 1,2 and 3 was not statistically significant. The second goal of this study was to determine the relationship between systolic blood pressure and RRI. According to data analysis by Pearson correlation coefficient $(\mathrm{P}=0.04)$, there is a significant relationship between increased blood pressure and RI. Further information is indicated in Table 4. The next goal of this study was to determine the relationship between diastolic blood pressure and RI. Pearson correlation coefficient showed no significant correlation between high blood pressure and RI ( $\mathrm{P}=0.32$; Table 4). Furthermore, Pearson test showed no significant correlation between high blood pressure and RRI $(\mathrm{P}=0.32)$. In this study, the

Table 1. Frequency of stages of diabetic nephropathy in the study population

\begin{tabular}{rrr}
\hline Stages & $\begin{array}{l}\text { of diabetic } \\
\text { nephropathy }\end{array}$ & Frequency \% \\
\hline $\mathbf{1}$ & 16 \\
$\mathbf{2}$ & 24 \\
$\mathbf{3}$ & 37 \\
$\mathbf{4}$ & 23 \\
Total & 100 \\
\hline & \\
\hline
\end{tabular}


Table 2. Systolic and diastolic blood pressure in each diabetic nephropathy stage

\begin{tabular}{lcr}
\hline & Systolic blood pressure & Diastolic blood pressure \\
\cline { 2 - 3 } Stage 1 & Mean \pm SD & Mean \pm SD \\
Stage 2 & $13 \pm 0.54$ & $8 \pm 0.33$ \\
Stage 3 & $0.24 \pm 12$ & $8 \pm 0.29$ \\
Stage 4 & $14 \pm 0.32$ & $10 \pm 0.51$ \\
\hline
\end{tabular}

Table 3. Comparison of RI in different stages

\begin{tabular}{lcc}
\hline & Mean \pm SD & P-Value \\
\hline Stage 1 & $0.66 \pm 0.05$ & \\
\hline Stage 2 & $0.69 \pm 0.04$ & \\
Stage 3 & $0.74 \pm 0.02$ & 0.001 \\
\hline Stage 4 & $0.85 \pm 0.09$ & \\
\hline
\end{tabular}

mean $\mathrm{HbA1C}$ for all diabetic nephropathy patients was $7.32 \pm 0.12$, which according to Pearson correlation coefficient $(\mathrm{P}=0.56)$, there was no significant correlation between HbA1C and RI (Table 4). According to data analysis, there is a significant relationship between increasing the amount of 24- $h$ urinary albumin excretion and RRI $(P=0.02$; Table 4). In addition, a significant correlation was found between increased GFR and RRI $(\mathrm{P}=0.001)$.

\section{Discussion}

The present study was a descriptive-analytic research at a specific time point in which association of RI variables such as HbA1C, GFR, systolic and diastolic blood pressure and albuminuria was evaluated in Doppler ultrasound based study in type 2 diabetic nephropathy stages. In this study, it seems that there is a direct relationship between the various stages of the disease with RI, where its increase has been demonstrated in diabetic nephropathy, especially at an advanced stage, which is consistent with many studies. ${ }^{29-32}$ Ohta (2006) indicated that RI of the renal arteries is linked to the severity of systemic atherosclerosis and is depend on underlying renal disease, and it seems to be more likely to increase in diabetic nephropathy ${ }^{31}$. Other studies demonstrated a considerable association of RI with glomerular lesions of typical or atypical diabetic nephropathy. ${ }^{32}$ RI $\geq 0.80$ has been defined as an independent predictor for decreasing renal function, indicating its value for determining risk of progressive renal disease in comparison with proteinuria and low
Table 4. Relationship between variables with RI

\begin{tabular}{|c|c|}
\hline $\begin{array}{c}\text { RRI } \\
\text { Variable }\end{array}$ & $\begin{array}{l}\text { The values of } r \text { and } \\
P \text { in Pearson's test }\end{array}$ \\
\hline Systolic blood pressure & $\begin{array}{l}\mathrm{P}=0.04 \\
\mathrm{r}=0.57\end{array}$ \\
\hline $\begin{array}{l}\text { Diastolic blood } \\
\text { pressure }\end{array}$ & $\begin{array}{l}\mathrm{P}=0.32 \\
\mathrm{r}=0.45\end{array}$ \\
\hline HbA1C & $\begin{array}{l}\mathrm{P}=0.56 \\
\mathrm{r}=0.43\end{array}$ \\
\hline $\begin{array}{l}\text { The amount of albumin } \\
\text { excretion in the } 24- \\
\text { hour urine }\end{array}$ & $\begin{array}{l}P=0.02 \\
r=0.67\end{array}$ \\
\hline GFR & $\begin{array}{l}P=0.001 \\
r=-0.76\end{array}$ \\
\hline
\end{tabular}

level of glomerular filtration, ${ }^{30}$ another study has emphasized the close association of RI with the progression of renal damage. ${ }^{33}$ Current evidence increased RI in patients suffering from primary hypertension is capable of demonstrating alteration of intrarenal perfusion, and systemic hemodynamics, providing prognostic data and therapeutic approach. ${ }^{34-36}$ Lower RI values have been indicated to attribute to blood pressure improvement, better renal function after the correction of renal-artery stenosis. ${ }^{34}$ In the present study, an increasing trend in blood pressure stage of the disease was seen in most cases. According to the data obtained from data analysis, there is a direct correlation between systolic blood pressure in diabetic nephropathy patients with RI, indicating that the increase in systolic blood pressure results in an increase in RI; these findings are in line with the findings of a number of studies. ${ }^{37-39}$. Based on the data presented herein, it does not seem that there is a significant relationship between diastolic blood pressure and RRI, although this is contradictory to the studies described above. In the past, genetic predisposition to high blood pressure has been indicated to be a factor for the presence and progression of diabetic nephropathy. ${ }^{37,40}$ Taniwaki et al.,2001 reported that RRI was positively linked to systolic and negatively to diastolic blood pressure, respectively. They indicated that RI was obtained based on the difference of intrarenal 
systolic with diastolic velocity of blood flow, suggesting its association with systolic and diastolic blood pressure. ${ }^{37}$ On the other hand, there were studies that reported no correlation between RI and blood pressure. $^{41,42}$ RI can be affected by age and pulse pressure, where an increase in RI was found to be independently linked to increased pulse pressure ${ }^{39}$ higher systemic 24-h blood pressure and circadian abnormalities. ${ }^{34}$ The well-known mechanism for increasing RRI in essential hypertension has not been explained._But various process can be likely involved in this event. Hypertensive arteriopathy has been described to be linked to constriction of arterioles and its hemodynamic modulation, thus both functional alteration and, renal atherosclerotic lesions has been attributed to an increase in RI value. ${ }^{39,43}$ Another goal of our study was to determine the relationship between $\mathrm{HbA1C}$ and RI, but the results showed that HbA1C levels cannot have a significant effect on the level of RI, and the values of these two variables are independent of each other. A study reported an association between $\mathrm{HbA1c}$ and increased RI in children with T1-DM. ${ }^{44}$ Another study indicated RRI was remarkably decreased in patients with T2D. Poor control of blood glucose, as shown by elevated $\mathrm{HbAlc}$ and basal plasma renin activity (PRA) had an effect on the magnitude of reduction in RI among subjects suffering from T2D. ${ }^{45}$ There are studies that reported RRI not associated with $\mathrm{HbA1c},{ }^{42,46,47}$ which are in agreement with our findings. In the present study, albuminuria in patients with diabetic nephropathy was calculated to be $296 \pm 12 \mathrm{mg} / 24 \mathrm{~h}$ which is classified as microalbuminuria and early macroalbuminuria. The results indicated a direct correlation of albumin excretion with RI. Thus, increasing the excretion of albumin has led to an increase in the resistance of the renal interlobular arteries. These findings are consistent with the results of many studies, ${ }^{29,32,48,49}$ which most studies emphasize RI role in reflecting intra-renal microvascular characteristics. ${ }^{50,51}$ Albuminuria (rate $\geq 30 \mathrm{mg} / 24 \mathrm{~h}$ ) has been defined to be a marker of kidney damage (National Kidney Foundation, 2002). $R I \geq 0.7$ has been defined to be capable of representing kidney function in diabetic patients with micro or macroalbuminuria. ${ }^{52,53}$ Microalbuminuria has been demonstrated to be valuable for predicting diabetic nephropathy and could serve as a clue for the onset of kidney damage. ${ }^{49}$ The association of RI with microalbuminuria in some investigations could suggest the impact of increased pulsatility on aorta, resulting in accelerating the gradual microvascular damage. ${ }^{51}$ As indicated previously, albuminuria was linked to RI, where its increase was observed in subjects with macroalbuminuria ( $>300 \mathrm{lg} / \mathrm{mg}$ creatinine) as compared with normoalbuminuria. ${ }^{26}$ Furthermore, increased RI has been revealed in diabetic nephropathy, when the kidneys become smaller in size, followed by microalbuminuria. ${ }^{54}$ On the other hand, recent evidence indicates that that albuminuria and albuminuric nephropathy cannot be always linked to impaired renal function and renal failure. ${ }^{18}$ A growing body of evidence suggests that high level of albuminuria or mild decrease in glomerular filtration rate (GFR) can be capable of assessing cardiovascular risk at the initial stage. ${ }^{55}$ Taken together, our results show that increasing systolic blood pressure, albumin excretion (microalbuminuria) and severity of disease were capable of increasing RI values in diabetic nephropathy patients. Furthermore, decreased GFR levels can increase RI values, but diastolic blood pressure and $\mathrm{HbA} 1 \mathrm{c}$ were not related to RI.

\section{List of acronyms}

CKD - Chronic Kidney Failure

DN - Diabetic nephropathy

GFR - glomerular filtration rate

PRA - plasma renin activity

PWV -pulse wave velocity

RI - Renal resistive index

RRTs - renal replacement programs

T2DM - type 2 diabetes

\section{Authors contributions}

SHSS, AL, AAM, FM, and BHGH conceived the study, performed the experiment, analyzed the data, wrote the paper and helped to editing the manuscript.

Acknowledgments None.

Funding No funding was obtained for this project.

\section{Conflict of Interest}

The authors declare no conflicts of interests.

\section{Ethical Publication Statement}

We confirm that we have read the Journal's position on issues involved in ethical publication and affirm that this report is consistent with those guidelines.

\section{Corresponding Author}

Sharareh Sanei Sistani, Department of Radiology, School of Medicine, Zahedan University of Medical Sciences, Zahedan, Iran

Email: sanei1345@yahoo.com

E-mails of co-authors

Ali Alidadi: alidadi@yahoo.com

Alireza Ansari Moghadam: rc_hp@zaums.ac.ir .

Fatemeh Mohamadnezhad:

fatemehmohamadnezhadmh@outlook.com

Bahareh Heshmat Ghahderijani: bahar.heshmatmd@gmail.com

\section{References}

1. Jha V, Garcia-Garcia G, Iseki K, et al. Chronic kidney disease: global dimension and perspectives. Lancet 2013;382(9888):260-72.

2. Gonzalez Suarez ML, Thomas DB, Barisoni L, Fornoni A. Diabetic nephropathy: Is it time yet for 


\section{Renal arterial resistive index}

Eur J Transl Myol 29 (4): 307-312, 2019

routine kidney biopsy? World J Diabetes 2013;4:245-55.

3. Lozano R, Naghavi M, Foreman K, et al. Global and regional mortality from 235 causes of death for 20 age groups in 1990 and 2010: a systematic analysis for the Global Burden of Disease Study 2010. Lancet 2013;380:2095-128.

4. Jha V. Current status of chronic kidney disease care in southeast Asia. Semin Nephrol2009; 29:487-96.

5. Eggers PW. Incidence of end-stage renal disease in the USA and other countries stabilized? Curr Opin Nephrol Hypertens 2011;20:241-5.

6. van der Velde M, Matsushita K, Coresh J, et al. Lower estimated glomerular filtration rate and higher albuminuria are associated with all-cause and cardiovascular mortality. A collaborative metaanalysis of high-risk population cohorts. Kidney Int 2011;79(12):1341-52.

7. Fox CS, Matsushita K, Woodward M, et al. Associations of kidney disease measures with mortality and end-stage renal disease in individuals with and without diabetes: a meta-analysis. Lancet 2012;380(9854):1662-73.

8. Matsushita K, van der Velde M, Astor BC, et al. Association of estimated glomerular filtration rate and albuminuria with all-cause and cardiovascular mortality in general population cohorts: a collaborative meta-analysis. Lancet 2010;375(9731):2073-81.

9. Ford ML, Tomlinson LA, Chapman TP, et al. Aortic stiffness is independently associated with rate of renal function decline in chronic kidney disease stages 3 and 4 . Hypertension 2010;55:1110-5.

10. Upadhyay A, Hwang SJ, Mitchell GF, et al. Arterial stiffness in mild-to-moderate CKD. J Am Soc Nephrol 2009;20:2044-53.

11. Ruggenenti P, Fassi A, Ilieva AP, et al. Preventing microalbuminuria in type 2 diabetes. N Engl J Med 2004;351:1941-51.

12. Katakami N, Osonoi T, Takahara M, et al. Clinical utility of brachial-ankle pulse wave velocity in the prediction of cardiovascular events in diabetic patients. Cardiovasc Diabetol 2014;13:128.

13. Won KB, Chang HJ, Kim HC, et al. Differential impact of metabolic syndrome on subclinical atherosclerosis according to the presence of diabetes. Cardiovasc Diabetol 2013;12:41.

14. Halpern EJ, Merton DA, Forsberg F. Effect of distal resistance on Doppler US flow patterns. Radiology 1998;206:761-6.

15. Derchi LE, Leoncini G, Parodi D, et al. Mild renal dysfunction and renal vascular resistance in primary hypertension. Am J Hypertens 2005;18:966-71.

16. Boddi M, Natucci F, Ciani E. The internist and the renal resistive index: truths and doubts. Intern Emerg Med 2015;10:893-905.
17. Ikee R, Kobayashi S, Hemmi N, et al. Correlation between the resistive index by Doppler ultrasound and kidney function and histology. Am J Kidney Dis 2005;46:603-9.

18. Afsar B, Elsurer R. Increased renal resistive index in type 2 diabetes: Clinical relevance, mechanisms and future directions. Diabetes Metab Syndr 2017;11:291-6.

19. Lubas A, Kade G, Niemczyk S. Renal resistive index as a marker of vascular damage in cardiovascular diseases. Int Urol Nephrol 2014;46:395-402.

20. Okura T, Kurata M, Irita J, et al. Renal resistance index is a marker of future renal dysfunction in patients with essential hypertension. J Nephrol 2010;23:175-80.

21. Mehrnahad M, Soleimantabar H, Sanei Taheri M, Ghahderijani BH. Pre-labor rupture of uterus at 32 weeks with extrusion of fetus with intact amniotic sac: a case report. J Inter Trans Med 2019;7:99102.

22. Mehrnahad M, Soleimantabar H, Ebrahimi A, Ghahderijani BH. Circumferential meningioma of the cervical spinal cord with widespread intracranial extension. J Res Med Dent Sci 2019;7: 44-6.

23. Jamaati HR, Heshmat B, Tamadon R, et al. Association between Severity of Chronic Obstructive Pulmonary Disease and Lung Function Tests. Tanaffos 2013;12:36-41.

24. Tublin ME, Bude RO, Platt JF. Review The resistive index in renal Doppler sonography: where do we stand? AJR Am J Roentgenol 2003;180:885-92.

25. Heine GH, Reichart B, Ulrich $\mathrm{C}$, et al. Do ultrasound renal resistance indices reflect systemic rather than renal vascular damage in chronic kidney disease? Nephrol Dial Transplant 2007;22:163-70.

26. Hamano K, Nitta A, Ohtake T, Kobayashi S. Associations of renal vascular resistance with albuminuria and other macroangiopathy in type 2 diabetic patients. Diabetes Care 2008;31:1853-7.

27. Chirinos JA, Townsend RR. Systemic arterial hemodynamics and the "renal resistive index": what is in a name? J Clin Hypertens 2014;16:170-1.

28. Naesens M, Heylen L, Lerut E, et al. Intrarenal resistive index after renal transplantation. $\mathrm{N}$ Engl $\mathrm{J}$ Med 2013;369:1797-806.

29. Nakamori A, Ando Y, Matsuda H, et al. Influence of proteinuria on renal Doppler sonographic measurements in chronic kidney disease and in diabetes mellitus. J Clin Ultrasound 2011;39:50611.

30. Radermacher J, Ellis S, Haller H. Renal resistance index and progression of renal disease. Hypertension 2002;39:699-703. 
31. Ohta Y, Fujii K, Arima H, et al. Increased renal resistive index in atherosclerosis and diabetic nephropathy assessed by Doppler sonography. J Hypertens 2006;23:1905-11.

32. Nosadini R, Velussi M, Brocco E, et al. Increased renal arterial resistance predicts the course of renal function in type 2 diabetes with microalbuminuria. Diabetes 2006;55:234-9.

33. Petersen LJ, Petersen JR, Talleruphuus U, et al. The pulsatility index and the resistive index in renal arteries. Associations with long-term progression in chronic renal failure. Nephrol Dial Transplant 1997; 12:1376 -80.

34. Viazzi F, Leoncini G, Derchi LE, Pontremoli R. Ultrasound Doppler renal resistive index: a useful tool for the management of the hypertensive patient. J Hypertens. 2014;32:149-53.

35. Hashimoto J, Ito S. Central pulse pressure and aortic stiffness determine renal hemodynamics: pathophysiological implication for microalbuminuria in hypertension. Hypertension 2011;58:839-46.

36. Pearce JD, Craven TE, Edwards MS, et al. Associations between renal duplex parameters and adverse cardiovascular events in the elderly: a prospective cohort study. Am J Kidney Dis 2010;55:281-90.

37. Taniwaki $\mathrm{H}$, Ishimura $\mathrm{E}$, Matsumoto $\mathrm{N}$, et al. Relations between ACE gene and ecNOS gene polymorphisms and resistive index in type 2 diabetic patients with nephropathy. Diabetes Care 2001;24:1653-6.

38. Petersen LJ, Petersen JR, Ladefoged SD, et al. The pulsatility index and the resistive index in renal arteries in patients with hypertension and chronic renal failure. Nephrol Dial Transplant 1995;10:2060-4.

39. Afsar B, Ozdemir NF, Elsurer R, Sezer S. Renal resistive index and nocturnal nondipping: is there an association in essential hypertension? Int Urol Nephrol 2009;41:383-91.

40. Pettitt DJ, Saad MF, Bennett PM, et al. Familial predisposition to renal disease in two generations of Pima Indians with type II (non-insulin dependent) diabetes mellitus. Diabetologia 1990;33:438-443.

41. Derchi LE, Martinoli C, Saffioti S, et al. Ultrasonographic imaging and Doppler analysis of renal changes in noninsulin-dependent diabetes mellitus. Acad Radiol 1994;1:100-5.

42. Ishimura E, Nishizawa $Y$, Kawagishi $T$, et al. Intrarenal hemodynamic abnormalities in diabetic nephropathy measured by duplex Doppler sonography. Kidney Int 1997;51:1920-7.

43. Jensen G, Bardelli M, Volkmann $\mathrm{R}$ et al. Renovascular resistance in primary hypertension: experimental variations detected by means of Doppler ultrasound. J Hypertens 1994;12:959-64.
44. Youssef DM, Fawzy FM. Value of renal resistive index as an early marker of diabetic nephropathy in children with type-1 diabetes mellitus. Saudi J Kidney Dis Transpl 2012;23:985-92.

45. Taniwaki H, Nishizawa Y, Kawagishi $\mathrm{T}$, et al. Decrease in glomerular filtration rate in Japanese patients with type 2 diabetes is linked to atherosclerosis. Diabetes Care 1998;21:1848-55.

46. Boeri D, Derchi LE, Martinoli C, et al. Intrarenal arteriosclerosis and impairment of kidney function in NIDDM subjects. Diabetologia 1998;41:121-4.

47. Matsumoto $\mathrm{N}$, Ishimura $\mathrm{E}$, Taniwaki $\mathrm{H}$, et al. Diabetes mellitus worsens intrarenal hemodynamic abnormalities in nondialyzed patients with chronic renal failure. Nephron 2000;86:44-51.

48. Fallah M, Nafisi-Moghadam R, Nouri N. Relationship between Intra-renal Arterial Resistance Index (RI) and Albuminuria in Diabetic Patients. IJDO 2012;4:7-10.

49. Adar A, Onalan O, Keles H, et al. Relationship between Aortic Arch Calcification, Detected by Chest X-Ray, and Renal Resistive Index in Patients with Hypertension. Med Princ Pract 2019;28:13340.

50. Raff U, Schmidt BM, Schwab J, et al. Renal resistive index in addition to low-grade albuminuria complements screening for target organ damage in therapy-resistant hypertension. J Hypertens 2010;28:608- 14.

51. Chirinos JA, Townsend RR. Systemic arterial hemodynamics and the "renal resistive index": what is in a name? J Clin Hypertens. 2014;16(3):170-1

52. Nosadini R, Velussi M, Brocco E, et al. Course of renal function in type 2 diabetic patients with abnormalities of albumin excretion rate. Diabetes, 2000;49:476-84.

53. Petersen LJ, Petersen JR, Talleruphuus U, et al. The pulsatility index and the resistive index in renal arteries. Associations with long-term progression in chronic renal failure. Nephrology Dialysis Transplantation 1997;12:1376-80.

54. Marzano MA, PompiliM, RapacciniGL, et al. Comparison of renal Doppler US and radioisotope evaluation of glomerular hyperfiltration. Radiology 1998;209:813-7.

55. Mancia G, De Backer G, Dominiczak A, et al. ESHESC Task Force on the Management of Arterial Hypertension 2007 ESH-ESC Practice Guidelines for the Management of Arterial Hypertension: ESH-ESC Task Force on the Management of Arterial Hypertension. J Hypertens 2007;25:175162.

Submission: June, 26, 2019

Acceptance: July 05, 2019 